\title{
Hypereosinophilic Syndrome
}

National Cancer Institute

\section{Source}

National Cancer Institute. Hypereosinophilic Syndrome. NCI Thesaurus. Code C27038.

A syndrome characterized by persistent eosinophilia, for which no underlying cause can be found, and which is associated with signs of organ involvement and dysfunction. This term has often been applied to cases of chronic eosinophilic leukemia. (WHO, 2001) 